2009-04

Design, manufacture, mechanical

\title{
testing and numerical modelling of an asymmetric composite crossbow limb
}

\section{Virk, AS}

http://hdl.handle.net/10026.1/11805

\subsection{6/j.compositesb.2008.10.004 \\ Composites Part B: Engineering \\ ELSEVIER SCI LTD}

All content in PEARL is protected by copyright law. Author manuscripts are made available in accordance with publisher policies. Please cite only the published version using the details provided on the item record or document. In the absence of an open licence (e.g. Creative Commons), permissions for further reuse of content should be sought from the publisher or author. 


\title{
Design, manufacture, mechanical testing and numerical modelling of an asymmetric composite crossbow limb
}

\author{
Amandeep S Virk ${ }^{\mathrm{a}}$, J Summerscales ${ }^{\mathrm{a}, \mathrm{b}}$, W Hall ${ }^{\mathrm{a}}$, S M Grove ${ }^{\mathrm{a}}$ and M E Miles ${ }^{\mathrm{a}}$ \\ ${ }^{a}$ School of Engineering, Reynolds Building, Drake Circus, \\ University of Plymouth, Plymouth, PL4 8AA, United Kingdom. \\ ${ }^{\mathrm{b}}$ communicating author
}

\begin{abstract}
This paper considers the design, manufacture, mechanical testing and numerical analysis of a crossbow beam (limb). The limb should be lightweight and permit a high deflection of the beam's tip in order to achieve a good ballistic performance. Consequently, fibre-reinforced polymer matrix composites are suitable candidate materials. However, carbon fibres were considered too brittle for this application. Aramid fibres combine low density and high stiffness but are weak in compression. E-glass fibres are relatively flexible but are of high density. The optimised design developed here uses aramid fibres on the tension face with E-glass fibres on the compression side. This component was manufactured using resin infusion, modelled using a commercial finite element code (Abaqus ${ }^{\circledR}$ ) and the model was validated by mechanical testing. A good correlation was found between the experimentally measured deflections and the numerical results.
\end{abstract}

Keywords: A: hybrid, B: mechanical properties, C: numerical analysis, crossbow limb

\section{Introduction}

Polymer matrix composites are the preferred materials in applications where high-strength and high-stiffness to weight ratios are required. Composite beams are used as load-carrying elements in high-performance aerospace, marine/naval, land transport, sport, mechanical (e.g. machinery) and civil (e.g. bridges) applications. Composites are useful where energy is stored and released in a controlled manner. This includes automotive leaf [1,2] and coil springs [3] and many sports goods [4-7]. For example, a crossbow limb stores the energy required to propel the arrow [8-10]. The traditional materials for the crossbow limb are wood or spring steel. Kooi et al. [8] state that "The efficiency of the bow is affected by the relative mass of the arrow when compared to that of the limb, but for an arrow of constant mass the lighter the limb the better the efficiency". Composites offer resilience, low structural weight, long service life and are not adversely 
affected by the environment. Thus a lightweight composite limb should outperform limbs of other materials.

This paper reports the design, manufacture using resin infusion, mechanical testing and numerical (Abaqus ${ }^{\circledR}$ finite element code) modelling of a crossbow beam (limb). This study was undertaken in the context of an undergraduate assignment for the BEng (honours) Mechanical Engineering with Composites degree. The time constraints did not permit consideration of shear stresses and strains at the load introduction and reaction points, or of the fatigue life.

\section{Preliminary Design Calculation}

Figure 1 shows the configuration of the key components of the crossbow. The limb deflection is a function of the draw length, $s$, limb length, $L$ and the braced position, $h$ [10]. A typical crossbow limb specification [11] requires that the limb must store sufficient energy to fire a bolt (arrow) of 22 grams, at an exit velocity of $100 \mathrm{~m} / \mathrm{s}$ with a power stroke, $d$, of $0.35 \mathrm{~m}$. The limb length is usually $\sim 0.4 \mathrm{~m}$ and is critical to the performance of the crossbow (Figure 1). Composite materials have high reliability and the loading and environmental conditions for crossbows are not severe therefore the Factor of Safety (FOS) for the limb only needs to be 1.5 [12].

The kinetic energy required for a bolt (mass, $m,=22 \mathrm{~g}$ and velocity, $v,=10 \mathrm{~m} / \mathrm{s}$ ) is,

$$
E=\frac{1}{2} m v^{2}=110 J
$$

The work done by a force, $F$, moving a body through a distance, $d$, is given by:

$$
E=F d
$$

The force is assumed to be a maximum at the start of the stroke and zero at the end. The requisite maximum force, $F_{H}$, can be estimated from Equations 1 and 2 (remembering that Figure 1b only shows half of the system).

$$
F_{H}=\frac{m v^{2}}{d}=630 N
$$

The relationship between the radius of curvature, $R$, and the other crossbow dimensions is given in Equation 4 where $N$ is half the chord length. The string is assumed to be inextensible [10] and the limb is assumed to bend in a circular arc. 


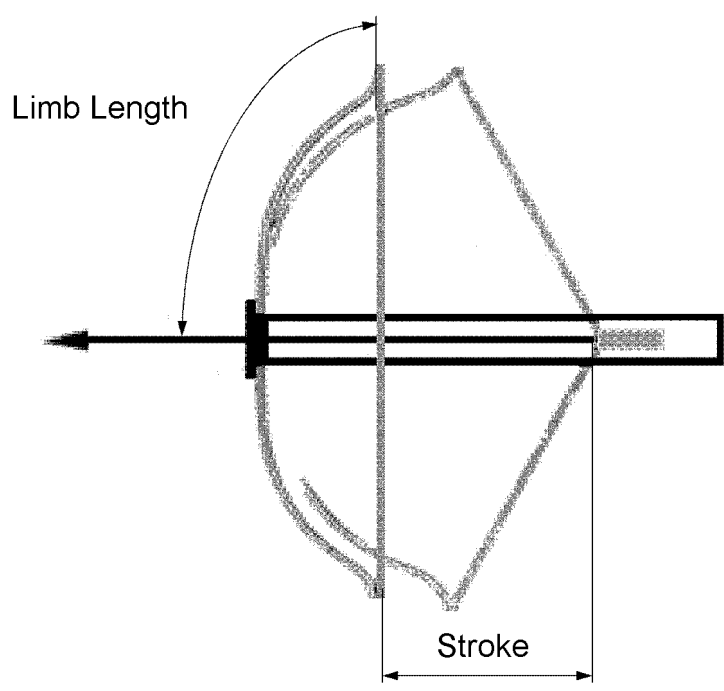

(a)

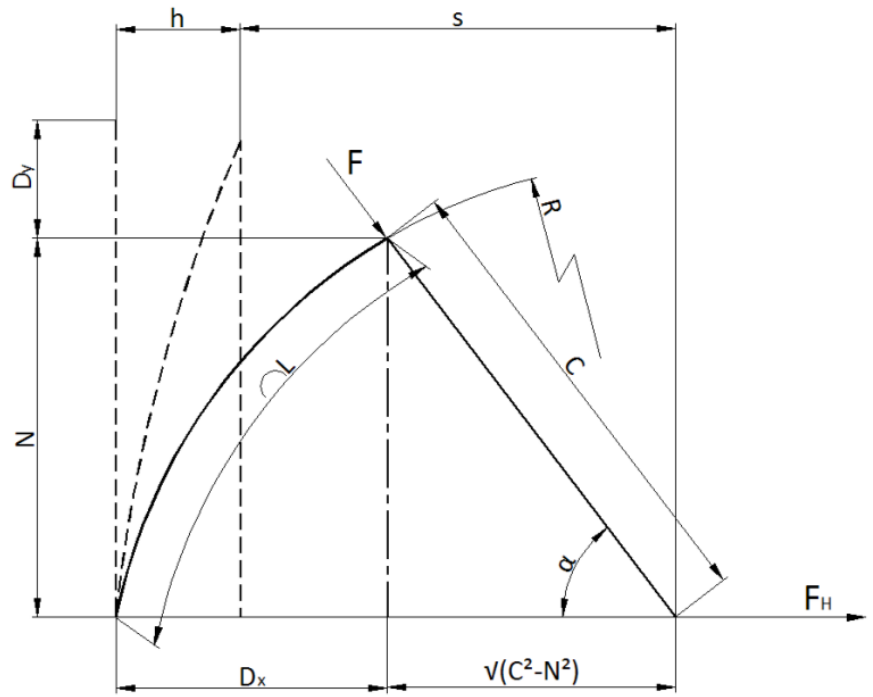

(b)

Figure 1: The cross bow (a) and

a schematic representation (b) of the crossbow at pre-firing position.

$R=\frac{h^{2}+s^{2}+C^{2}+2 h s-2 h \sqrt{C^{2}-N^{2}}-2 s \sqrt{C^{2}-N^{2}}}{2\left(h+s+\sqrt{C^{2}-N^{2}}\right)}$

$\sin \alpha=\frac{N}{C}$

$L=R \sin ^{-1}\left(\frac{N}{R}\right)$

$D_{x}=h+s-\sqrt{C^{2}-N^{2}}$

$D_{y}=L-N$

The force acting on the arrow, $F_{H}$, is a function of the angle between the string and the arrow, $\alpha$. At rest $\alpha$ is $90^{\circ}$, but as the string is drawn the angle decreases as shown in Figure 2, and the deflections in the $x$ and $y$ directions are given by $D_{X}$ and $D_{Y}$ respectively. The normalised force acting on the arrow is also shown in Figure 2. This normalised force is a function of the end load 
of the beam, $F$, and is given by Eq. 9 [10]; the shape of the graph is similar to that given by Kooi et al. $[8,10]$.

$F_{H}=F \cos \alpha$

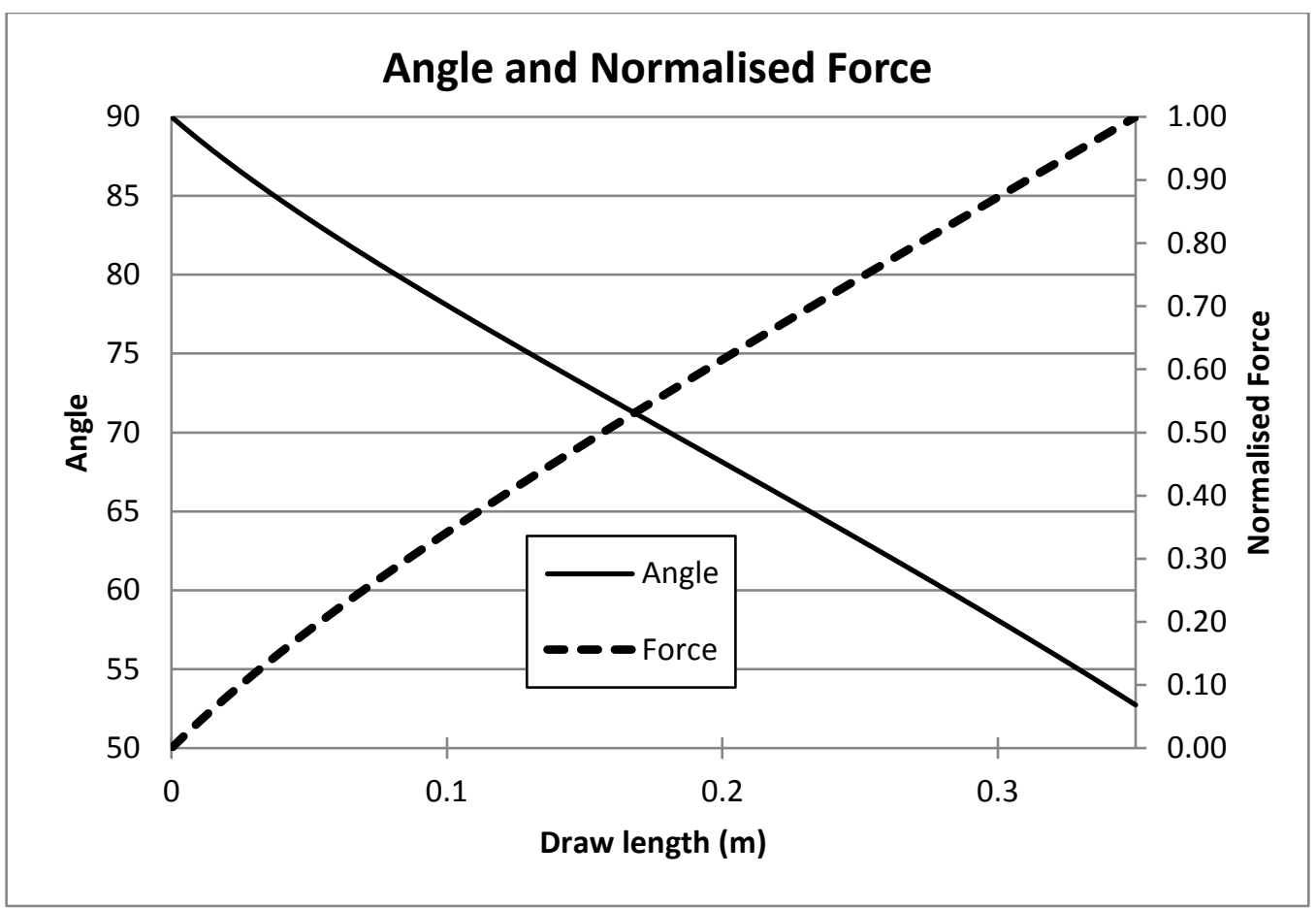

Figure 2: Variation of force and angle between string and arrow as string is drawn

The reinforcement options considered for the limb (Table 1) were carbon, E-glass and/or aramid fibre as monolithic or hybrid composites, or cored sandwich constructions. The limb was loaded at the end (bending load) and hence it carries a direct tensile load on the outer face and a compressive load on the inner face. Therefore unidirectional fibres oriented parallel to the beam axis will provide maximum stiffness [13]. Unidirectional (UD) carbon fibres offer highest specific modulus [13] and hence the lightest weight limb but are too brittle. E-glass fibres offer the highest strain to failure [14] which makes the limb more tolerant to higher deflection but results in the highest weight. Aramid fibres have low compression strength [14-16] although the tensile modulus of the fibre is double that of E-glass fibres [14]. Thus, a potential solution to satisfy the specification of this component is to combine the E-glass and aramid fibres to make a hybrid composite beam. The outer tension face of the beam can be reinforced by aramid fibres 
(with their higher tensile modulus) whilst the inner compressive face can be reinforced by Eglass fibres.

Table 1: Potential design options

\begin{tabular}{|l|l|l|l|l|l|}
\hline & Design 1 & Design 2 & Design 3 & Design 4 & Design 5 \\
\hline Outer (tension) & Carbon & Carbon & E-glass & Aramid & Aramid \\
\hline Centre & Carbon & Core & E-glass & Core & E-glass \\
\hline Inner (compression) & Carbon & Carbon & E-glass & E-glass & E-glass \\
\hline
\end{tabular}

The limb was considered as a cantilever beam loaded at the free end. A fibre volume fraction $\left(V_{f}\right)$ of $55 \%$ was anticipated for the unidirectional reinforcement in order to estimate material properties using rules of mixture [17] (Appendix 1). This $V_{f}$ was subsequently found to be an underestimate given the chosen manufacturing route.

Beam theory cannot be directly applied to calculate the cross-section of the beam as the Young's moduli of the layers differs. The cross-section of the limb was transformed considering the Young's modulus of each of the layers and then the position of the neutral axis of the beam was calculated. The second moment of area was determined about the neutral axis and used to obtain an initial cross-section for the limb [18].

Equation 7 predicts that for a $0.4 \mathrm{~m}$ long limb the required deflection is $0.22 \mathrm{~m}$ (under a load of $315 \mathrm{~N}$ per limb - see Equation 3) to get a power stroke of $0.35 \mathrm{~m}$. The width of the limb was fixed at $0.05 \mathrm{~m}$ as this is a standard width for reinforcement tape. This reduces material wastage and also manufacturing time as no cutting is required to get the required width. Beam flexural stiffness increases linearly with width (breadth) whereas the stiffness is a function of thickness (depth) cubed. To achieve a given flexural stiffness it is therefore more weight efficient to increase thickness rather than width. On the other hand, a narrower limb will deflect more [19] resulting in a reduced FoS with respect to fibre failure strain. Under end loading, the maximum strain of the limb is near the restrained end. Typical failure strains for the fibres are given in 
Table 2. Table 3 shows the required cross-section of the beam to fulfil the geometrical (length and width) and stiffness (deflection under prescribed load) specifications. The corresponding maximum predicted strains are also given in the table.

Table 2: Fibre failure and design strains [13]

\begin{tabular}{|l|c|c|}
\hline & Fibre Failure Strain $\left(\varepsilon^{\prime}\right)$ & Design Strain $\left(\varepsilon^{\prime} / 1.5\right)$ \\
\hline Carbon (High-strength) & $1.10 \%$ & $0.73 \%$ \\
\hline E-glass & $2.60 \%$ & $1.73 \%$ \\
\hline Aramid (Kevlar & & $1.53 \%$ \\
\hline
\end{tabular}

Table 3 : Limb size and maximum strain, (c) $=$ carbon fibres, (a) = aramid fibres, $(\mathrm{g})=$ E-glass fibres

\begin{tabular}{|l|c|c|c|c|c|}
\hline & Design 1 & Design 2 & Design 3 & Design 4 & Design 5 \\
\hline Total Thickness & $0.0048 \mathrm{~m}$ & $0.0051 \mathrm{~m}$ & $0.007 \mathrm{~m}$ & $0.0066 \mathrm{~m}$ & $0.0064 \mathrm{~m}$ \\
\hline Outer & $0.0048 \mathrm{~m}$ & $0.0017 \mathrm{~m}$ & $0.007 \mathrm{~m}$ & $0.0022 \mathrm{~m}$ & $0.0021 \mathrm{~m}$ \\
\hline Centre & - & $0.0017 \mathrm{~m}$ & - & $0.0022 \mathrm{~m}$ & - \\
\hline Inner & - & $0.0017 \mathrm{~m}$ & - & $0.0022 \mathrm{~m}$ & $0.0043 \mathrm{~m}$ \\
\hline Maximum Strain (outer) & $1 \%(\mathrm{c})$ & $1 \%(\mathrm{c})$ & $1.43 \%(\mathrm{~g})$ & $1.10 \%(\mathrm{a})$ & $1.14 \%(\mathrm{a})$ \\
\hline Maximum Strain (inner) & $-1 \%(\mathrm{c})$ & $-1 \%(\mathrm{c})$ & $-1.43 \%(\mathrm{~g})$ & $-1.60 \%(\mathrm{~g})$ & $-1.49 \%(\mathrm{~g})$ \\
\hline
\end{tabular}

The maximum strain in Designs 1 and 2 (those based on carbon fibres) are $\pm 1 \%$ and the failure strain of carbon fibre is $1.1 \%$ [13]. This design does not offer a FOS of 1.5 and is hence not an option. The hybrid composite beam (Design 5) is seen as the 'best' choice as it satisfies geometrical, stiffness and material strength (strain) specifications. It offers a FOS of 1.7 in the glass section and of 2.0 in the aramid section. The thicknesses for the aramid and E-glass layers were calculated such that the aramid layer was always in tension [18]. The limb was stiffened near the restrained (compression) end by an additional four layers of E-glass (see Figure 3). The clamped length was $0.05 \mathrm{~m}$. 


\section{Prototype manufacturing}

A prototype ( $0.475 \mathrm{~m}$ long) was manufactured by resin infusion with a flow medium/distributor mesh [20-24] using $0.05 \mathrm{~m}$ wide unidirectional aramid and E-glass tapes. A flat glass plate was used as a mould as the undeformed designed crossbow limb was straight. The aramid reinforcement was laid directly on the pre-released mould surface, E-glass tape was laid on top of aramid tape and then the two E-glass end reinforcement layers (Figure 3). The manufacturing setup without vacuum bag is shown in Figure 4.

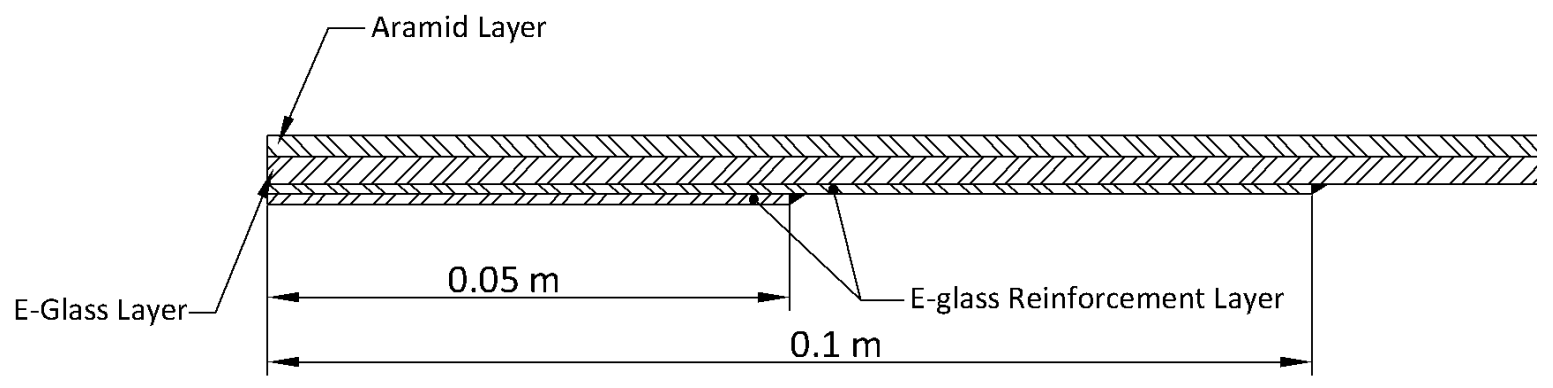

Figure 3 : Reinforcement layers near the limb end for strengthening

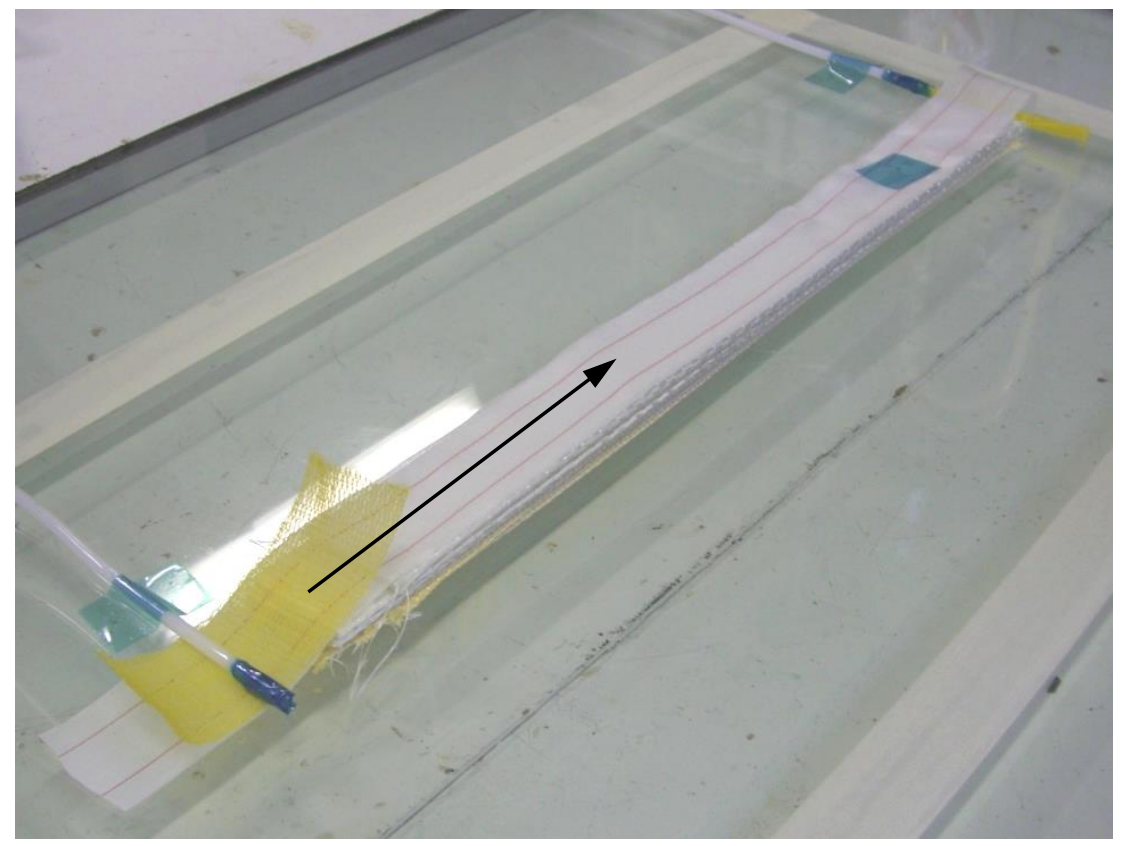

Figure 4: Manufacturing setup without vacuum bag.

The arrow shows the resin infusion direction 
To achieve the desired thickness of the product nine layers of aramid tape $\left(194 \mathrm{~g} / \mathrm{m}^{2}\right)$ and six layers of E-glass fibre tape $\left(657 \mathrm{~g} / \mathrm{m}^{2}\right)$ were used. The longitudinal stiffness of the limb is of key importance and thus care was taken to ensure the fibre was straight and parallel to the beam axis. The infusion resin system was Sicomin ${ }^{\mathrm{TM}} 8100$ epoxy resin with SH8422 hardener [34]. The resin was infused from the thicker end of the limb. The infusion rate was controlled to ensure that (a) the fibre alignment was not distorted, (b) the fibres were completely wetted (for optimum fibre adhesion to the matrix) [19] and (c) the void volume fraction was minimised. The plate was cured for $24 \mathrm{~h}$ at ambient temperature. Then the resin manufacturer recommended cure cycle $\left(10^{\circ} \mathrm{C} / \mathrm{h}\right.$ ramp to $60^{\circ} \mathrm{C}, 16 \mathrm{~h}$ at $60^{\circ} \mathrm{C}$ then $1 \mathrm{~h}$ ramp down to ambient temperature) was followed with the vacuum maintained in the bag throughout the cure cycle.

The chosen design used both glass and aramid fibres which have different axial coefficients of thermal expansion [13]. This could lead to curvature of the component, especially where elevated temperature cure is involved. However, the component produced for this study was cured at low temperature and no significant curvature in the axial direction was observed. Similarly, the radial coefficient of thermal expansion of aramid fibre is higher that that of glass fibre [13] which could lead to longitudinal splitting of the limb. No longitudinal splitting was observed in the final product.

\section{Testing}

\section{Fibre volume fraction}

The samples of the beam were cast into potting compound (epoxy resin) and polished to 6 micron diamond. The microstructure was examined using an Olympus BX60 optical microscope and analySISTM image analysis software. Micrographs of the cross-section of the prototype limbs were used to estimate the fibre volume fractions [20]. A typical micrograph is shown in Figure 5. The thickness of the E-glass and aramid layers was measured separately from the micrographs using the image analysis software (analySISTM). 


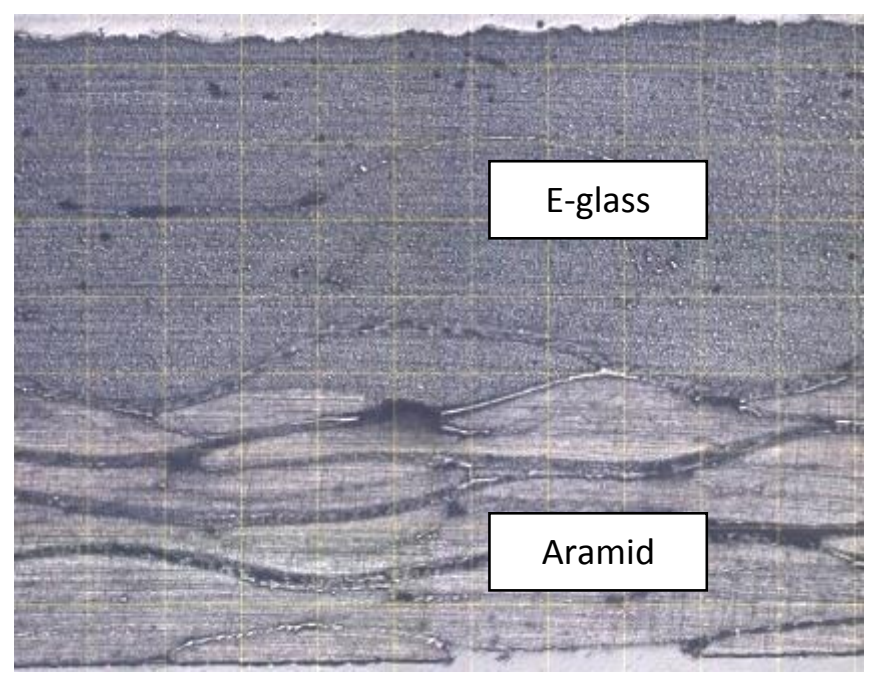

Figure 5 : Cross section of preproduction sample (the grid is $0.5 \mathrm{~mm}$ )

Using optical microscopy the fibre volume fractions for the E-glass and the aramid layers were estimated as $63.5 \%$ and $67 \%$ respectively. A resin burn-off test [20,25] was used to confirm the E-glass fibre volume fractions: a fibre volume fraction of $60 \%$ was measured, slightly below that calculated using optical microscopy but within the bounds of experimental error.

\section{Deflection Test}

To derive experimental load-deflection characteristics, the $0.475 \mathrm{~m}$ long crossbow limb was clamped for $0.05 \mathrm{~m}$ (half the length of the thickened section as shown in Figure 3) with dead weight loads applied via a G-clamp at $\sim 0.425 \mathrm{~m}$ from the clamped end. Masses were hung from the G-clamp a further $0.05 \mathrm{~m}$ from the G-clamp position - see Figure 6 (and Figure 11). The average beam thickness was $4.6 \mathrm{~mm}$ ( $2 \mathrm{~mm}$ aramid and $2.6 \mathrm{~mm}$ E-glass) for the main body and $5.4 \mathrm{~mm}(2 \mathrm{~mm}$ aramid and $3.4 \mathrm{~mm}$ E-glass) at the thick end. Deflections in the $x$ - and $y$-axes were noted for each load increment at the G-clamp position ' $\mathrm{X}$ ' (0.425 $\mathrm{m}$ from the fixed end). The total deflection $D$ was calculated from $x$ and $y$ deflections using $D=\sqrt{ }\left(x^{2}+y^{2}\right)$ as shown in Figure 7.

The experimental beam was examined to establish that there was no delamination at the ply drop-off. 

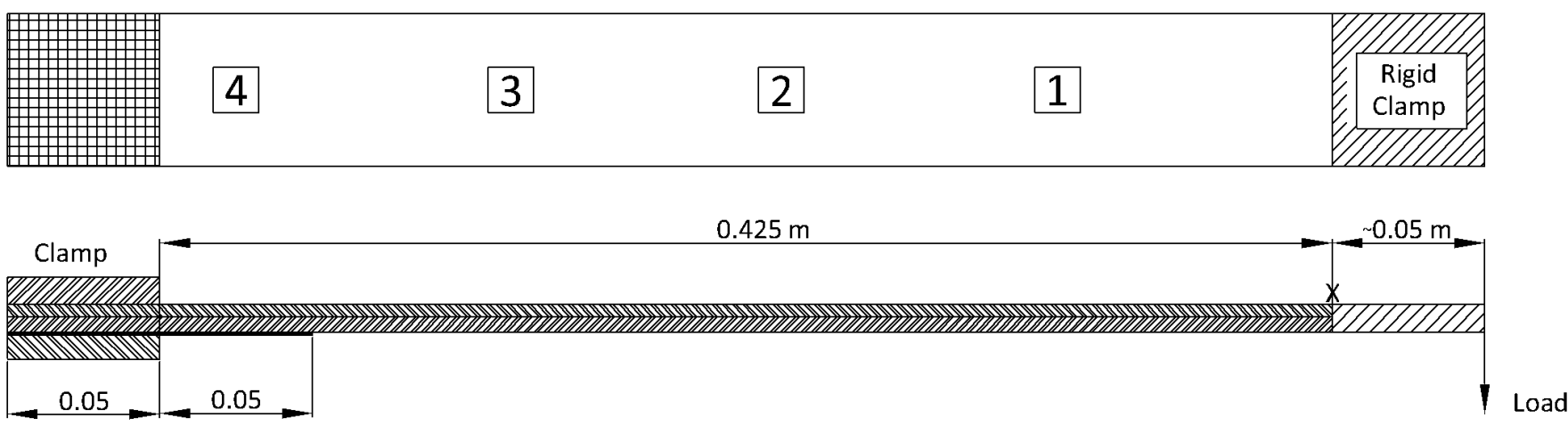

Not to Scale

Figure 6: Test setup for sample including strain gauge positions $(1,2,3 \& 4)$

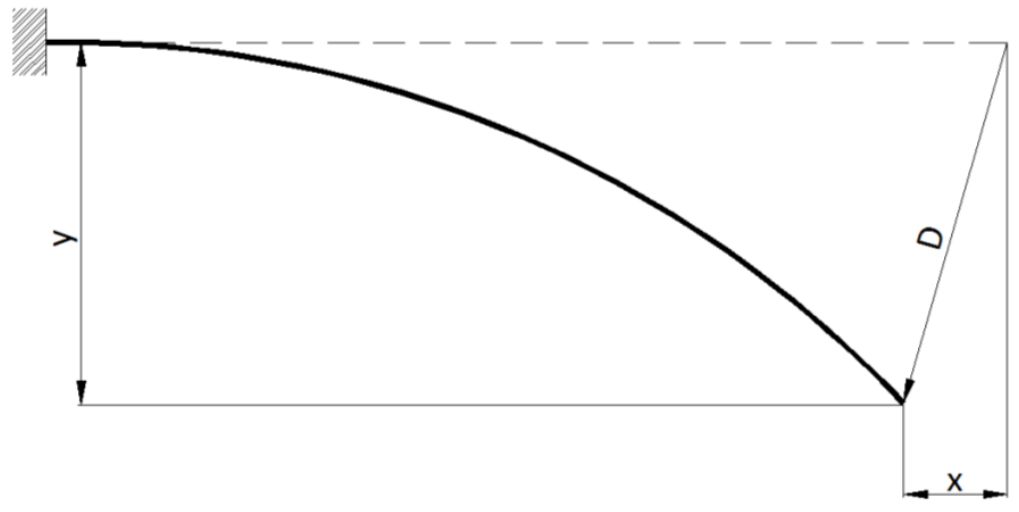

Figure 7 : Deflection calculation of the limb

\section{Numerical analysis}

The response of the structure to mechanical load was simulated using Abaqus ${ }^{\circledR}$ finite element software. The Finite Element model used the experimental sample dimensions. The limb was modelled using 3-D elements ('S8R': 8-node double curvature quadratic thick shell elements, reduced integration [30]). The material properties for the composite layers were calculated using the rule-of-mixtures with approximate fibre volume fractions $(60 \%$ and $65 \%$ for E-glass and aramid respectively see Appendix 1) and standard fibre properties from Daniel and Ishai [17]. The quadratic element formulation was selected as it can simulate a curved geometry more accurately and is known to perform better than the linear counterparts [28, 29, 31]. A structured mesh using rectangular shell elements was used as it is more computationally efficient than any other element shape [31, 32]. The model was meshed with 1050 elements. The force load of 350 
$\mathrm{N}$ was applied in the FE model at $0.475 \mathrm{~m}$ from the clamped end shown in Figure 8, which also shows the $0.05 \mathrm{~m}$ G-clamp position was modelled with rigid elements. The FE model is shown in Figure 8.

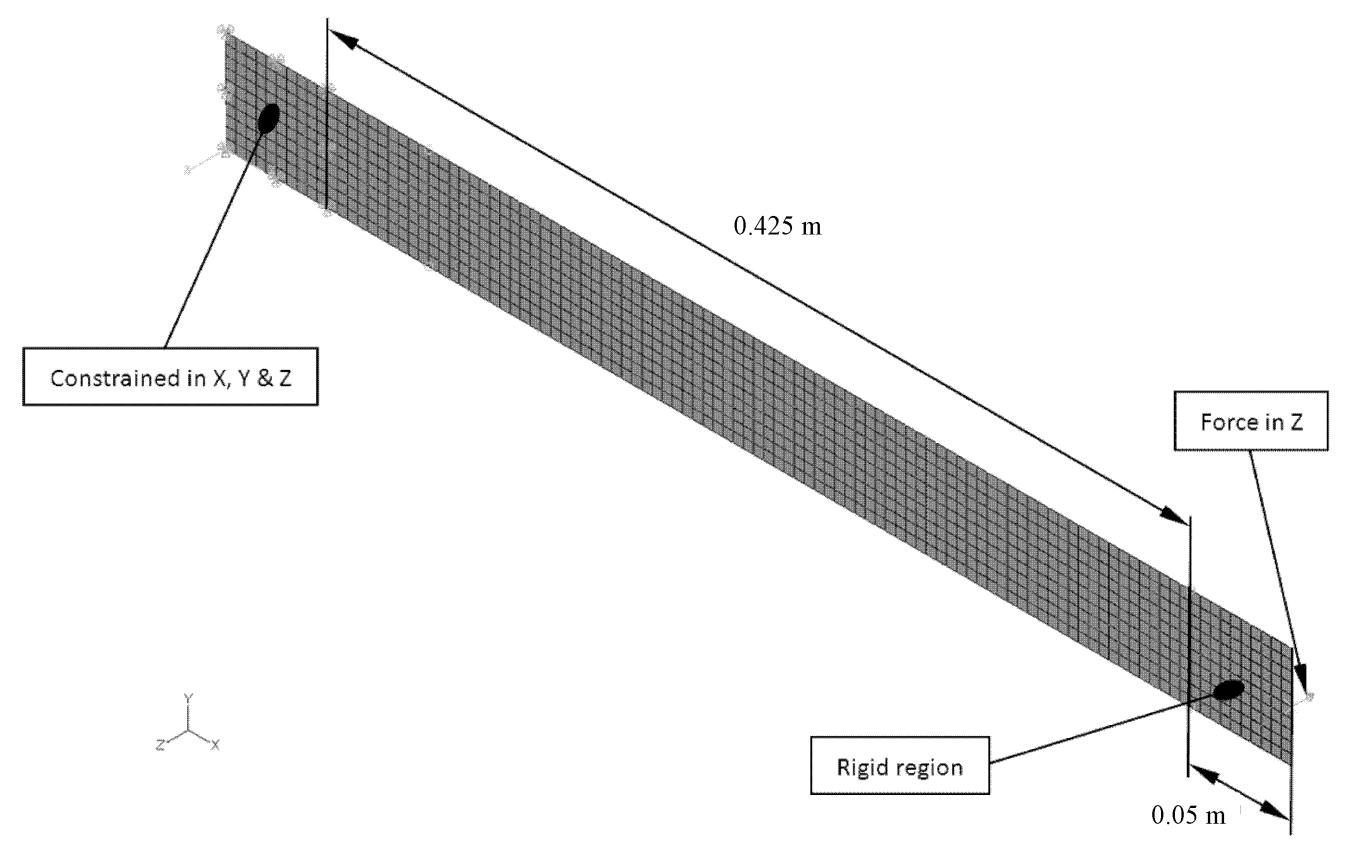

Figure 8 : Finite element model

Since the beam deflections were large, geometric non-linearity was used [29, 33]. The computational time was 16 minutes on a dual-core $2 \mathrm{GHz}$ computer. The experimental and FEA load-deflection characteristics are compared in Figure 9. The experimental beam stiffness and FEA predictions (identified by the slope) both show a similar non-linear response with the experimental deflection being only $6 \%$ above the predicted value at the upper load. 


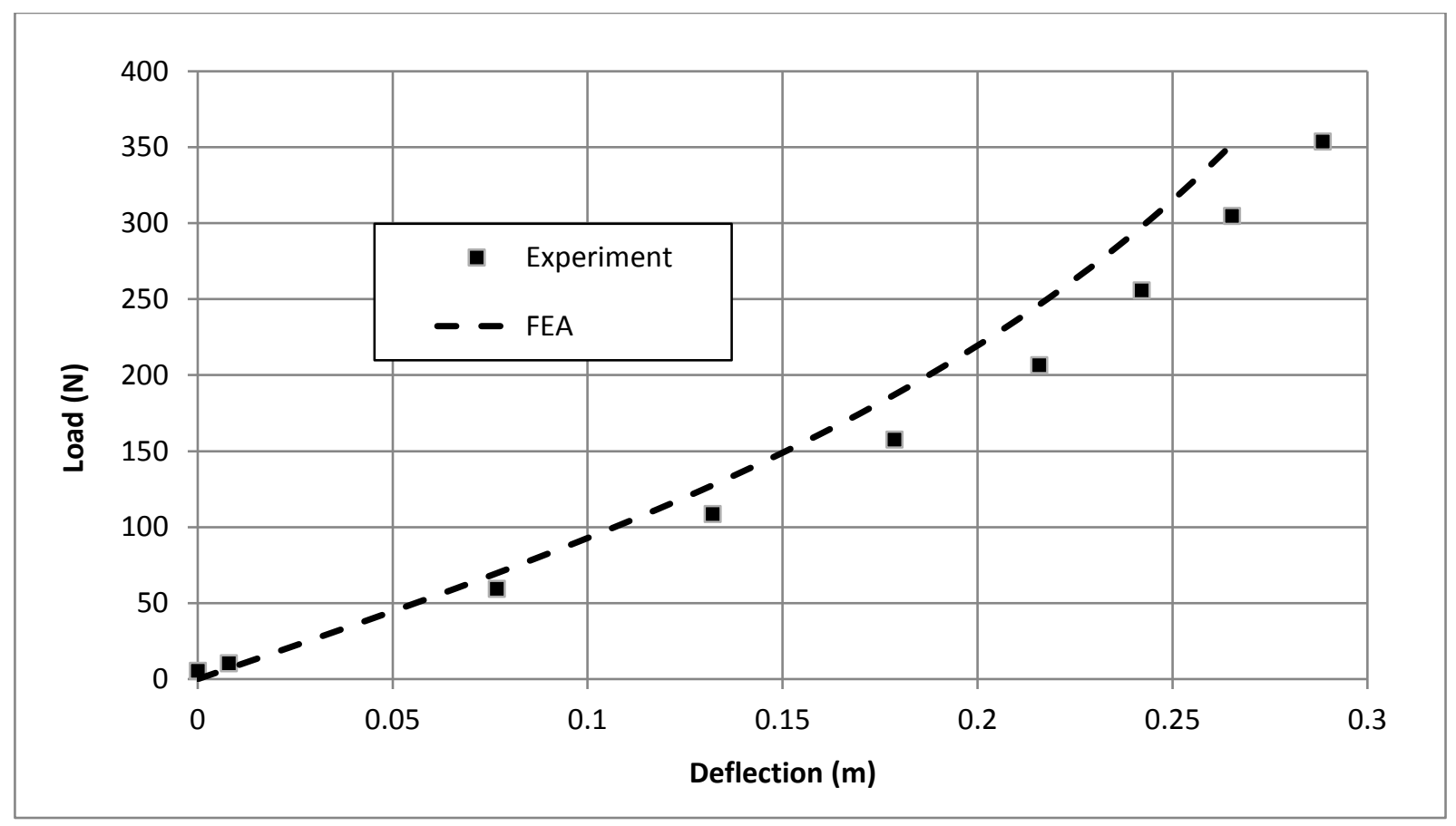

Figure 9 : Experimental and FEA deflection response of the limb

\section{Strain Measurement}

Strain in the limb was measured using 4 three-element $0^{\circ} / 45^{\circ} / 90^{\circ}$ strain gauges (Showa

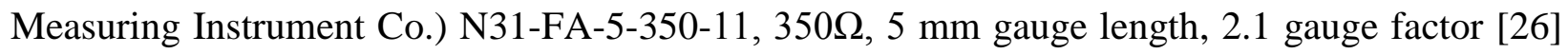
as shown in Figure 10. The test setup is shown in Figure 11. A Vishay P3 strain indicator and recorder were used to record the strain measurements at five load increments up to $350 \mathrm{~N}$. All strain gauges were mounted on the aramid face only.

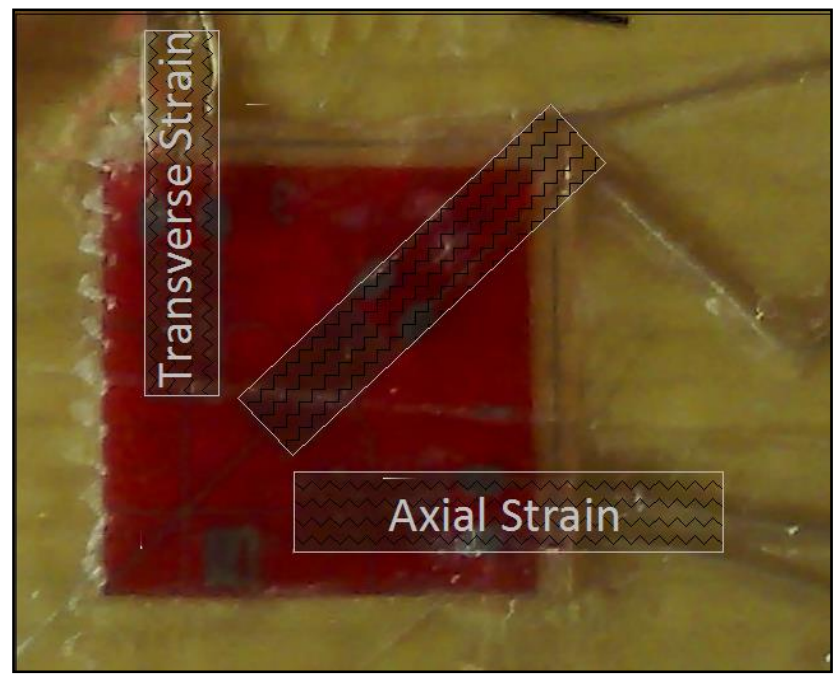

Figure 10 : Strain gauge orientation 


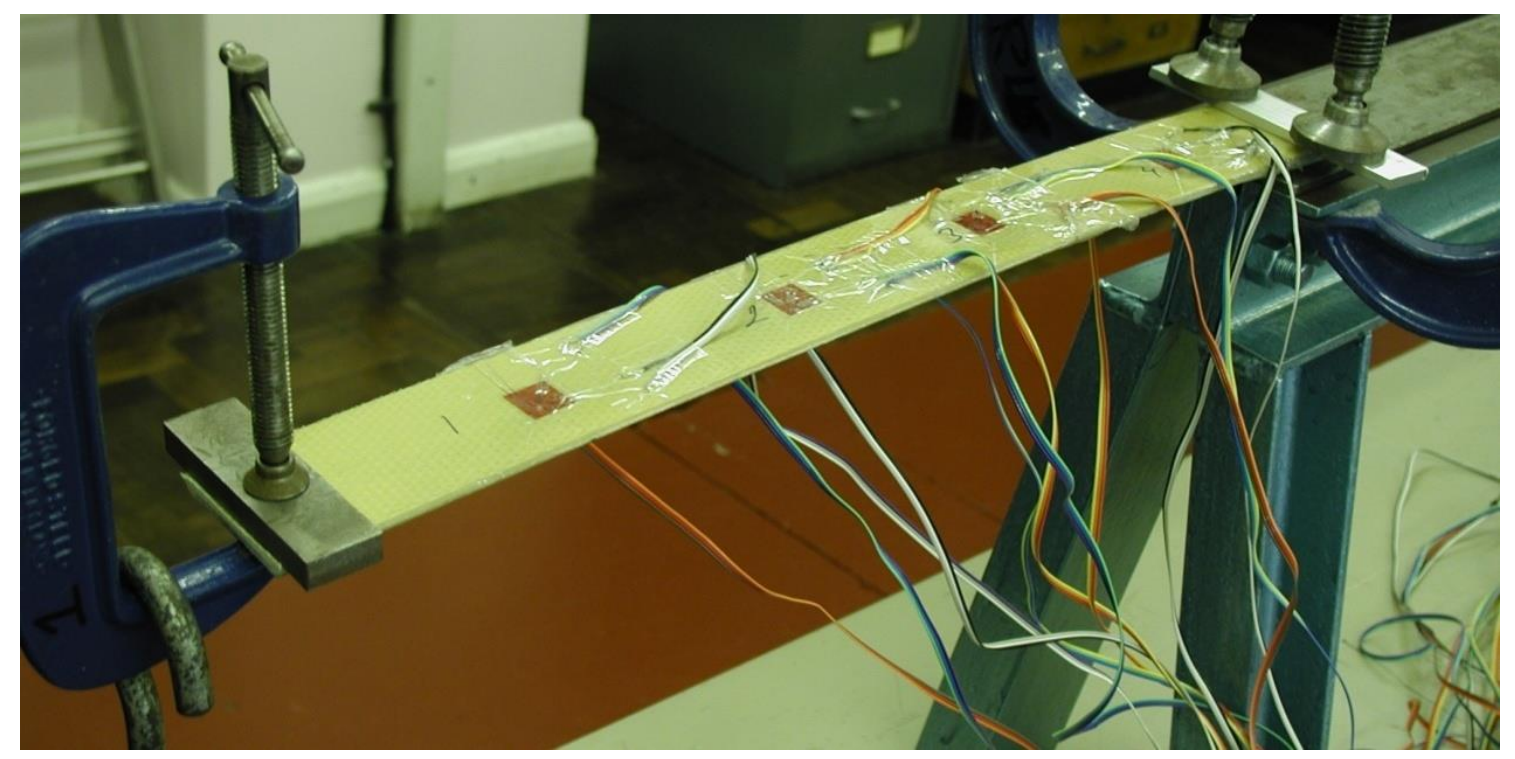

Figure 11 : Test setup for design 2

A three-wire quarter bridge strain gauge circuit was used to measure the strain. The longitudinal strain and the transverse strain on the aramid (tensile) surface were measured and are shown in Figure 12 and Figure 13 respectively. The drop in the strain at strain gauge 4 is due to the increase in the thickness of the beam near the clamped end (extra E-Glass layers). 


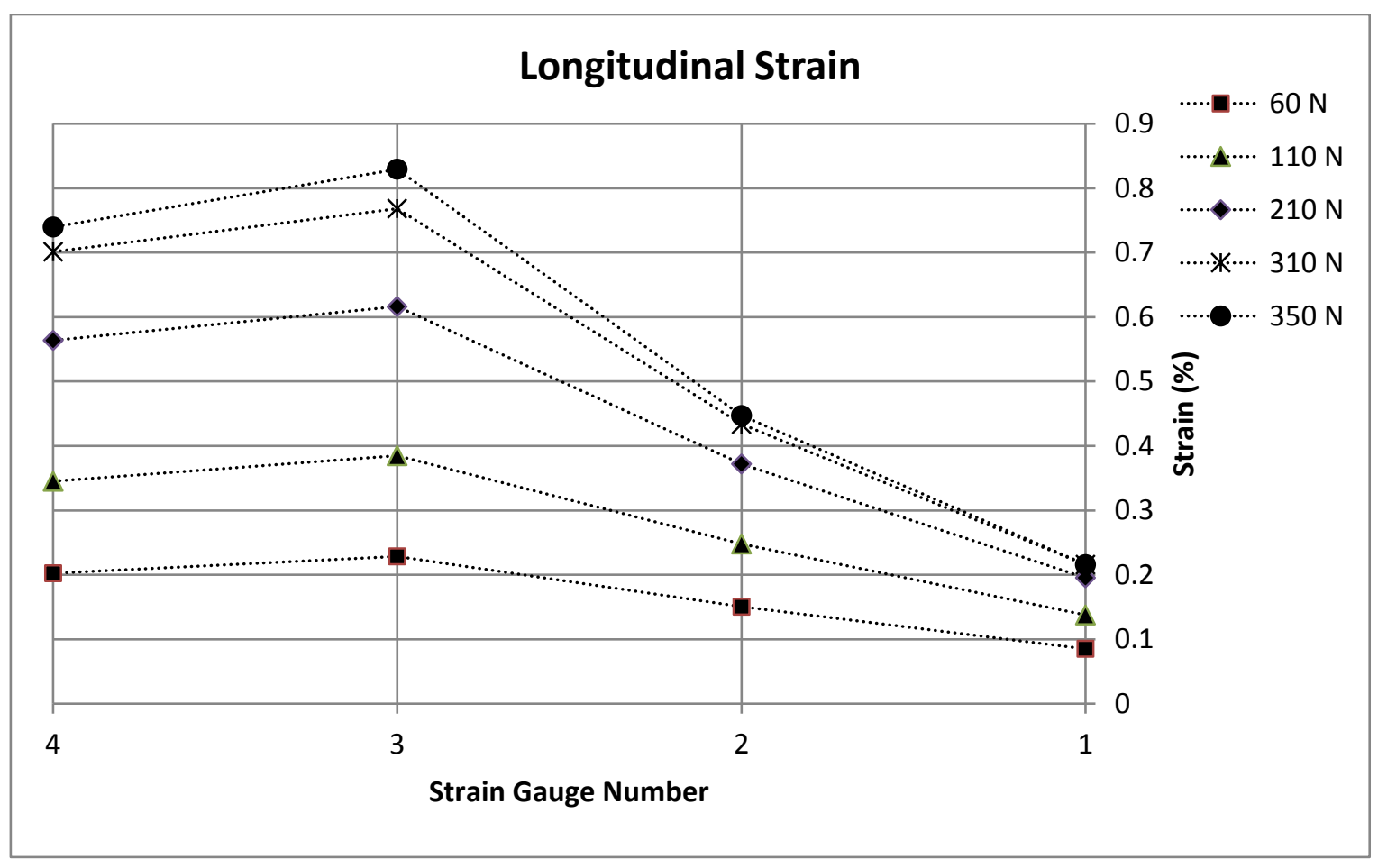

Figure 12 : Direct strain in longitudinal direction at different load (points at the same load connected by dotted lines for ease of interpretation)

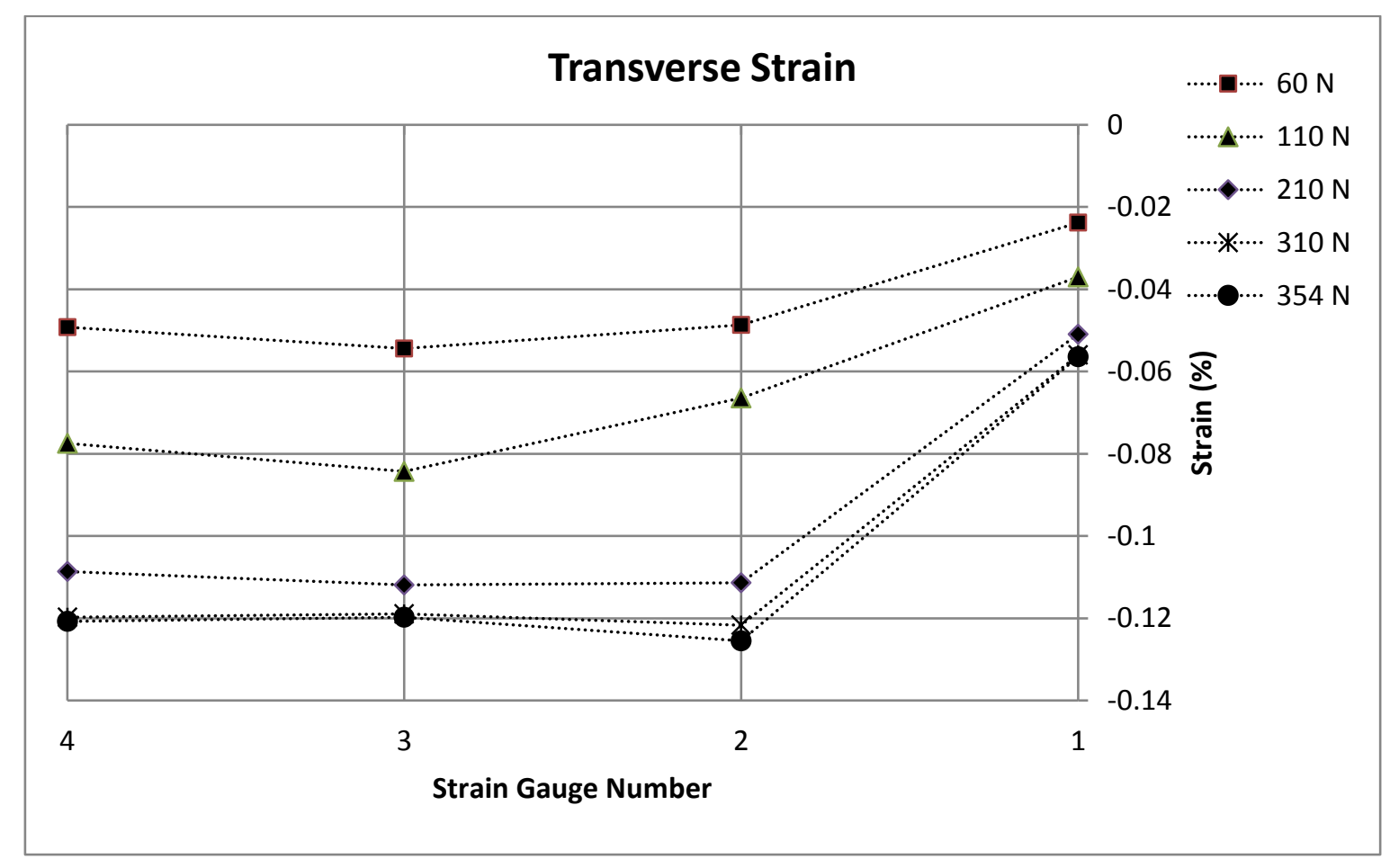

Figure 13 : Transverse strain at different loads 
The measured transverse strain is due to the Poisson contraction. The ratio of absolute transverse strain and longitudinal strain (Poisson ratio $v_{12}$ ) measured on the aramid (tension) face of the beam was plotted against the longitudinal strain for strain gauges 3 and 4. As the load (and hence strain) increases the Poisson's ratio decreases as shown in Figure 14 as previously reported for fibreglass composites in reference [27]. The linear regression lines (calculated using the least squares method) drawn through the points and extrapolated back to zero longitudinal strain gives Poisson's ratios of 0.277 and 0.274 for strain gauges 3 and 4 respectively. Note that this value of Poisson's ratio differs from the values used in the numerical analysis which is 0.34 (Appendix 1) calculated using rule of mixture [17]. Higher values of Poisson's ratio used for numerical simulation will affect the stiffness matrix calculated during the FEA solution.

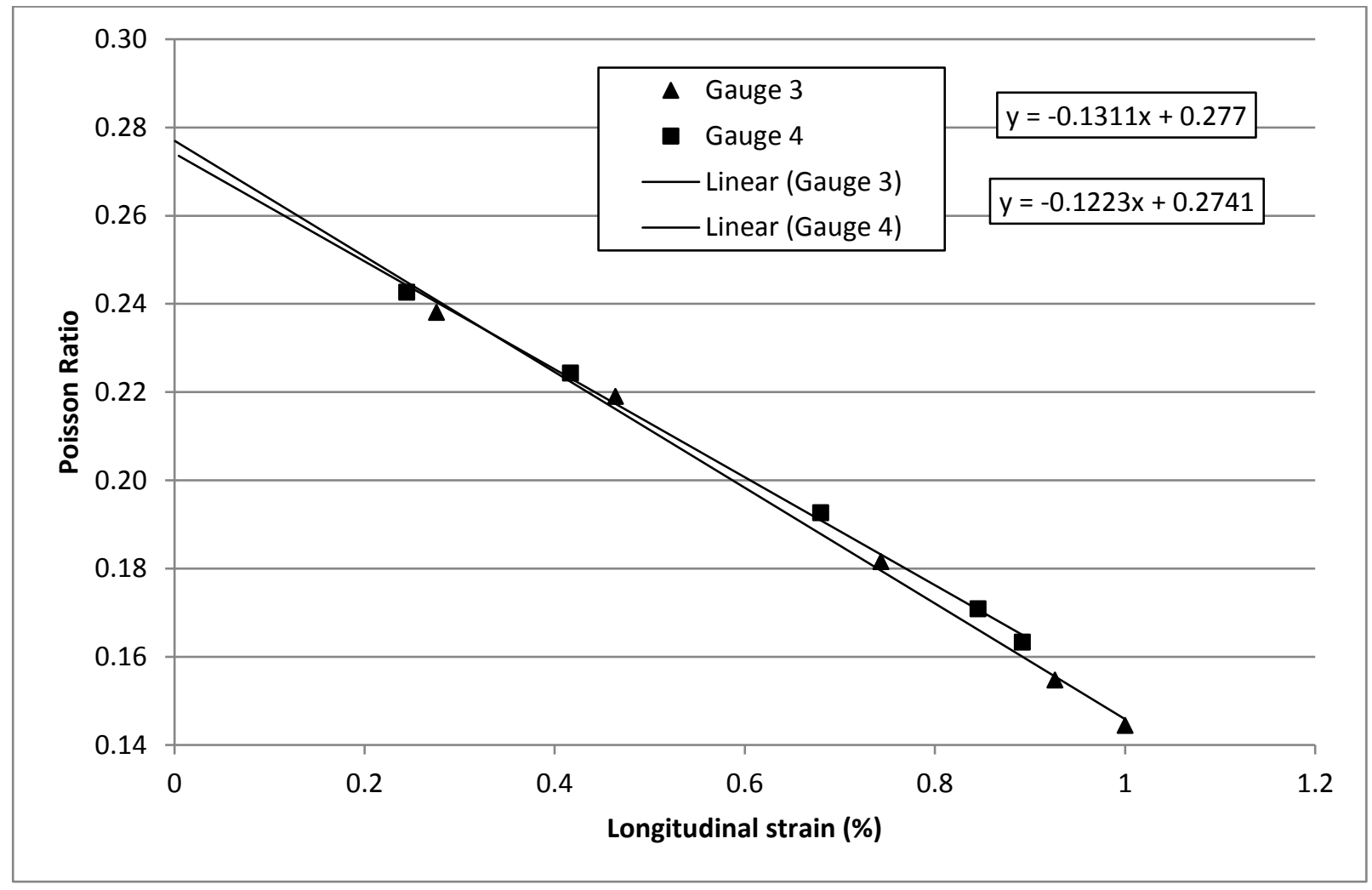

Figure 14 : Ratio of transverse and longitudinal strain

The numerical analysis of the limb showed good agreement with the measured strains. The predicted (FEA) direct strains on the surface/interface in the fibre direction (along the beam length) and deflection (D) under 350N load are given in Table 4. 
Table 4 : Direct strain in fibre direction and Maximum deflection predicted by FEA

\begin{tabular}{|c|c|c|}
\hline Layer & Longitudinal Strain & Max-Deflection \\
\hline Aramid & $0.92 \%$ & \multirow{2}{*}{$0.275 \mathrm{~m}$} \\
\hline Interface & $0.17 \%$ & \\
\hline E-glass & $-1.29 \%$ & \\
\hline
\end{tabular}

The experimental strain distribution at the maximum force of $350 \mathrm{~N}$ was compared to the corresponding numerical strain predictions. Experimental and FEA results were in good agreement (see Figure 15). The predicted strain on the tensile surface at the G-clamped end ( $0.05 \mathrm{~m}$ from the end of the beam) was zero, but increased rapidly with distance from the clamped end up to $0.055 \mathrm{~m}(\varepsilon=0.8 \%)$. Beyond this point, and up to $0.1 \mathrm{~m}$, the strain decreased linearly as the thickness of the limb remained constant. At $0.1 \mathrm{~m}$ the strain increases up to $0.92 \%$ (maximum strain) as the thickness of the limb is reduced (see Figure 3). The strain variation is approximately linear beyond this point up to the tip of the limb $(0.475 \mathrm{~m})$. This correlates well with the discrete measured points (see Figure 15).

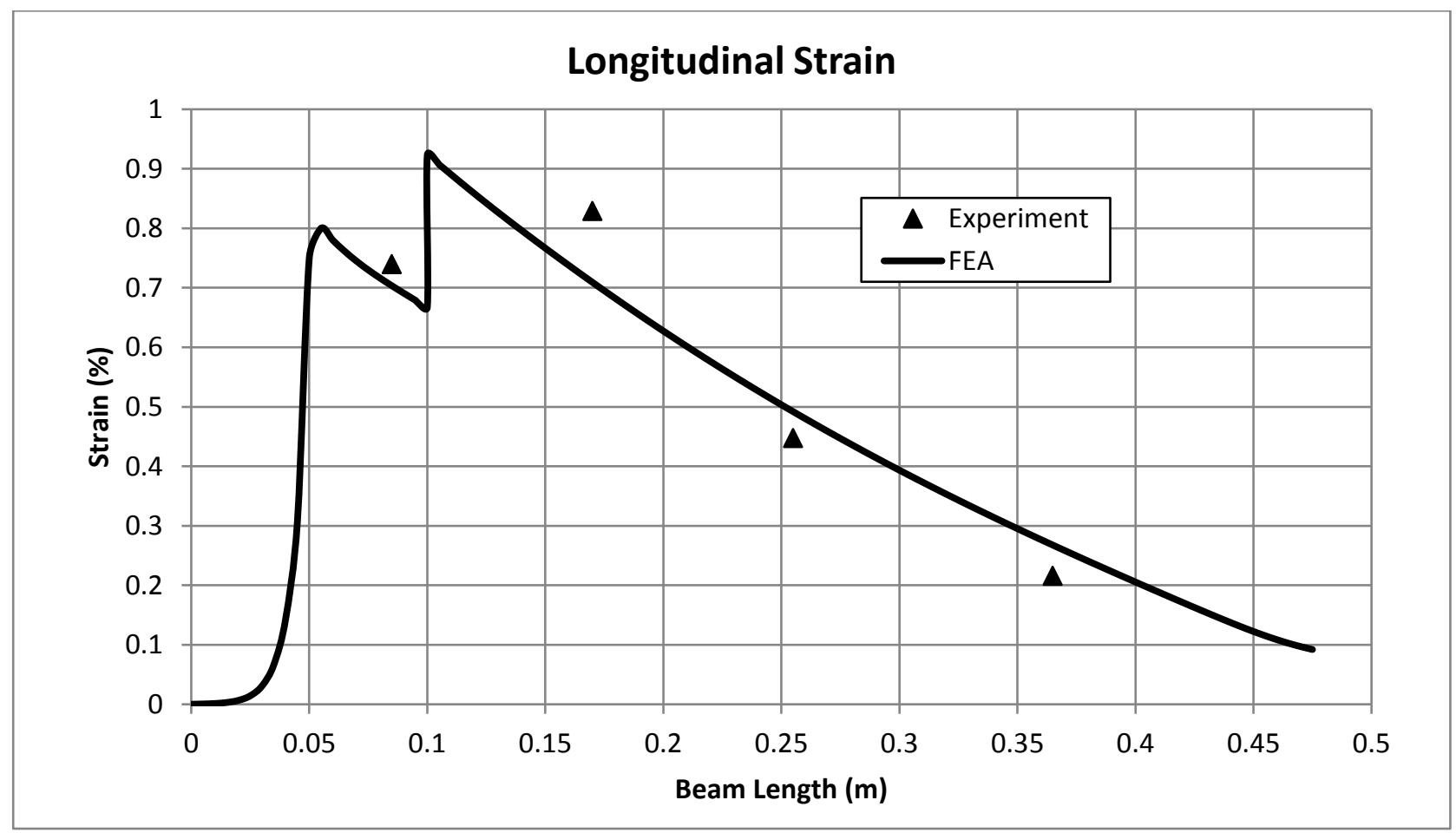

Figure 15 : Strain along the length of the aramid face of the limb 


\section{Design Optimisation}

An initial design had been produced for the crossbow limb based on a commercial product specification. A prototype had been manufactured and its behaviour accurately simulated, providing confidence in the modelling methodology. This allowed the authors to produce a complete finite element representation of a crossbow (with a $0.4 \mathrm{~m} \mathrm{limb}$ ). The new model (see Figure 16) was used to calculate the energy imparted by the limb to the arrow. The cross section and the material properties of the crossbow limb were the same as for the prototype. The limb was meshed using the same 3-D elements ('S8R': 8-node double curvature quadratic thick shell elements, reduced integration [30]).

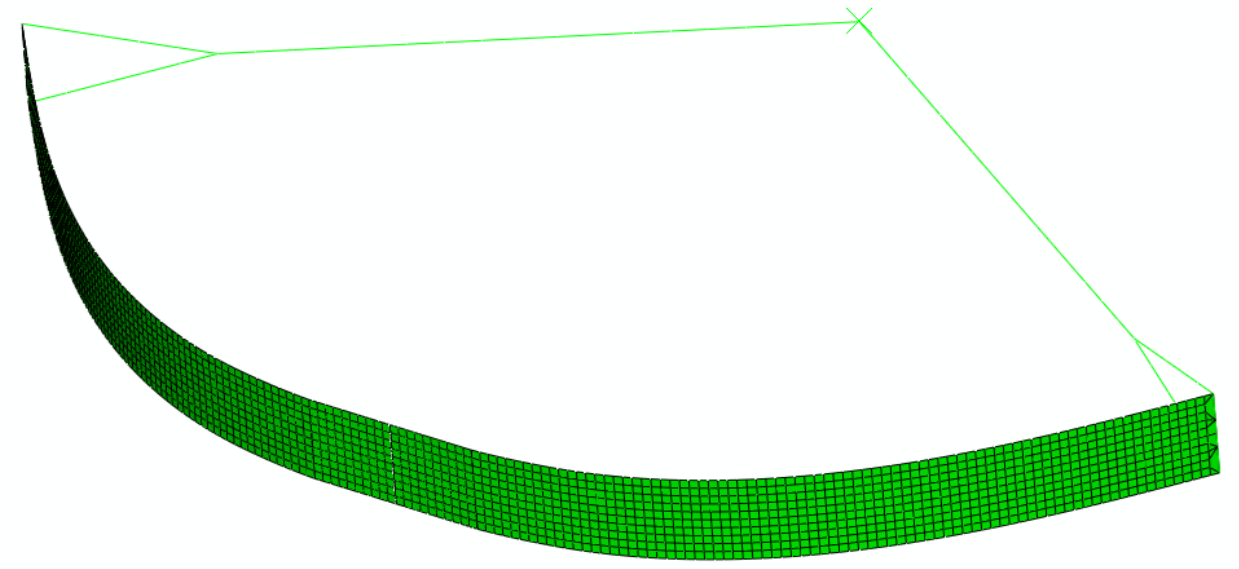

Figure 16 : 0.4 m limb model

The variation in the total draw force (given by 2 limbs) with the draw length is shown in Figure 17. A polynomial trend line was established (based on a least squares approximation [35]) to get the relation between stroke positions and the draw force. The equation is shown on the plot in Figure 17. The energy delivered by the limb can be calculated in terms of stroke position (s) by integrating the equation of force $[18,35]$.

Force, $F=-19230 s^{4}+20484 s^{3}-6378 s^{2}+1575 s-0.097$

Energy, $E=\int F d s$

$E=\int\left(-19230 s^{4}+20484 s^{3}-6378 s^{2}+1575 s-0.097\right) d s$

$E(s)=-3846 s^{5}+5121 s^{4}-2126 s^{3}+\frac{1575 s^{2}}{2}-0.097 s$

$E(0.35)=61.93$ Joules 


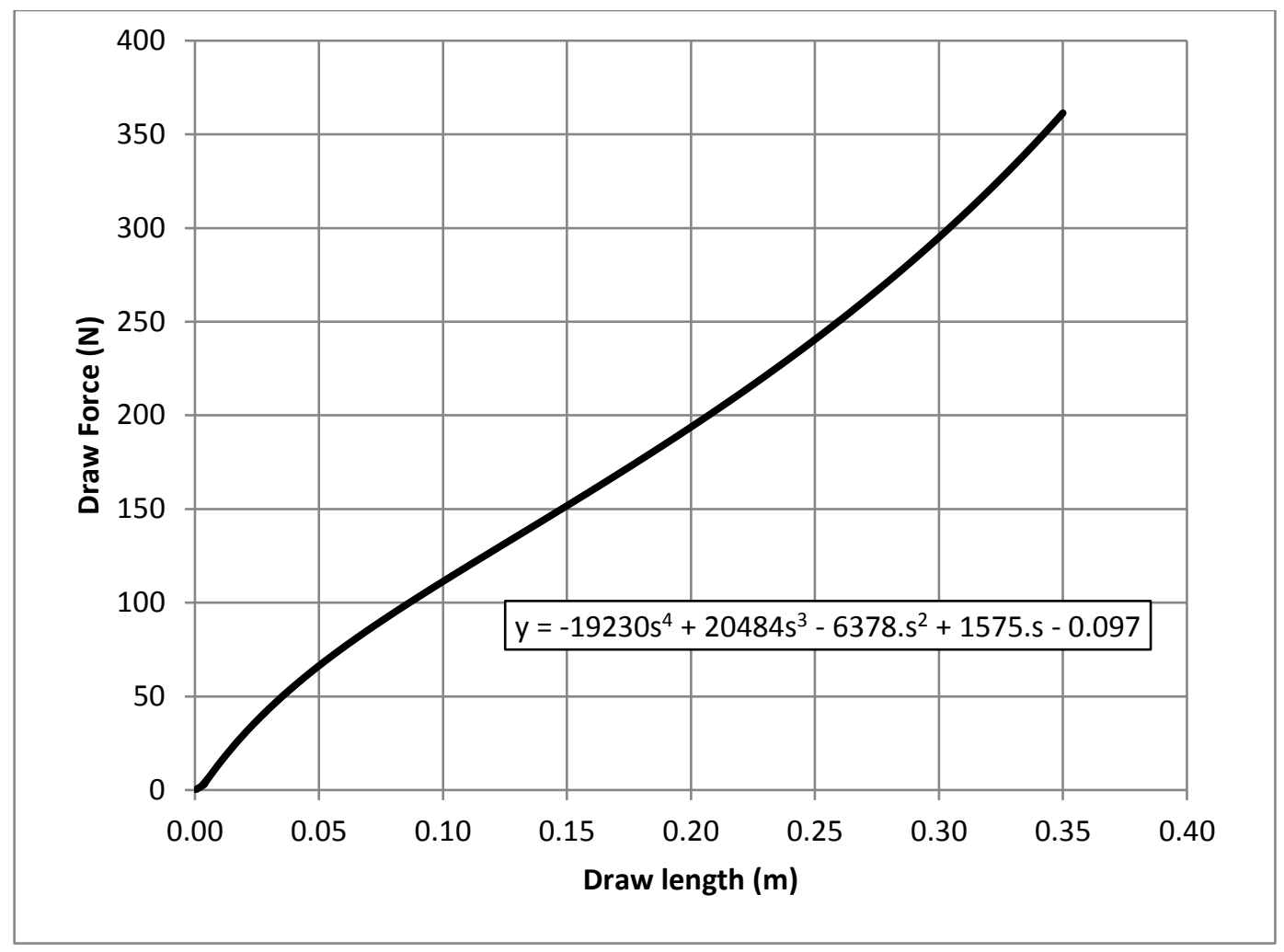

Figure 17 : Draw force vs. Stroke length for initial design

The energy delivered by the crossbow (i.e. $61 \mathrm{~J}$ ) was roughly half (1.8) the energy required i.e. $(110 \mathrm{~J})$. Therefore the design in its existing form will not meet the requirements. To fulfil the specification the stiffness of the limb ( $k=$ force/deflection) has to be doubled (see Eq. 14). However, the deflection response of the limb is non-linear due to the large deflection and the stiffness of the limb cannot be calculated using this linear beam theory. The stiffness for the nonlinear beam can be estimated by differentiating the force with respect to deflection (Eq. 14). A polynomial trend line shown in Figure 18 is drawn through the force deflection curve to estimate the relation between the applied deflection and the reaction force, given in Eq. 15.

$k=\frac{\text { Force }}{\text { Deflection }}=\frac{d F}{d x}$

$f(x)=25298 x^{4}-3703 x^{3}+929.6 x^{2}+774.2 x+.352$

The stiffness of the existing beam is given by Eq. 16 (by differentiating Eq. 15). The stiffness of the cross-bow shown in Figure 17 at $0.25 \mathrm{~m}$ deflection is $2125.8 \mathrm{~N} / \mathrm{m}$, Eq. 17. 


$$
\begin{aligned}
& k=\left(25298 x^{4}-3703 x^{3}+929.6 x^{2}+774.2 x+.352\right) d x \\
& k=1011192 x^{3}-11109 x^{2}+1859.2 x^{2}+774.2 \\
& k_{0.25}=2125.8 \mathrm{~N} / \mathrm{m}
\end{aligned}
$$

The stiffness of each limb at $0.25 \mathrm{~m}$ deflection is $1062.9 \mathrm{~N} / \mathrm{m}$.

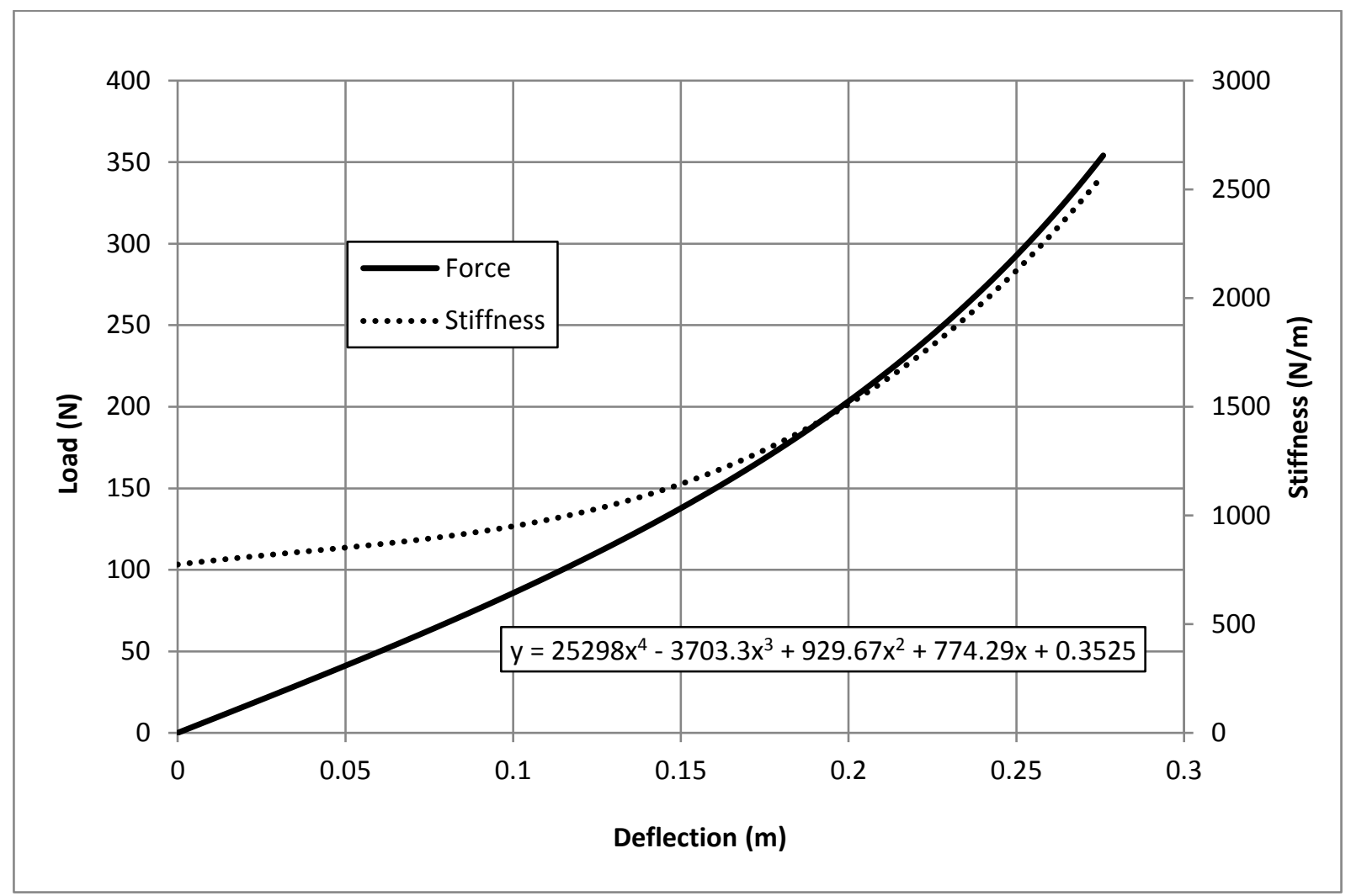

Figure 18 : Deflection response and Stiffness variation with deflection

To increase the energy output, the requisite limb stiffness is estimated to be $1920 \mathrm{~N} / \mathrm{m}$ (from $1063 \times 1.8=1913$ ) at $0.25 \mathrm{~m}$ beam end deflection (a total stiffness for the two limbs of approximately $3830 \mathrm{~N} / \mathrm{m}$ ). To achieve this, the necessary cross section was found by increasing the thickness of each layer by $\sqrt[3]{1.8}$. The final cross sectional dimensions of the main beam are given in Table 5. The E-glass reinforced end thickness is increased from $3.4 \mathrm{~mm}$ to $4.2 \mathrm{~mm}$ (see Figure 3). The FEA model was updated for the new cross section and the simulation was repeated. The simulated draw force against draw length for the updated model is shown in Figure 19. 
Table 5 : Strain distribution in the limb

\begin{tabular}{|c|c|c|}
\hline Layer & Thickness & FEA Strain \\
\hline Aramid & $0.0025 \mathrm{~m}$ & $0.82 \%$ \\
\hline Interface & & $0.1 \%$ \\
\hline E-glass & $0.0034 \mathrm{~m}$ & $-1.1 \%$ \\
\hline
\end{tabular}

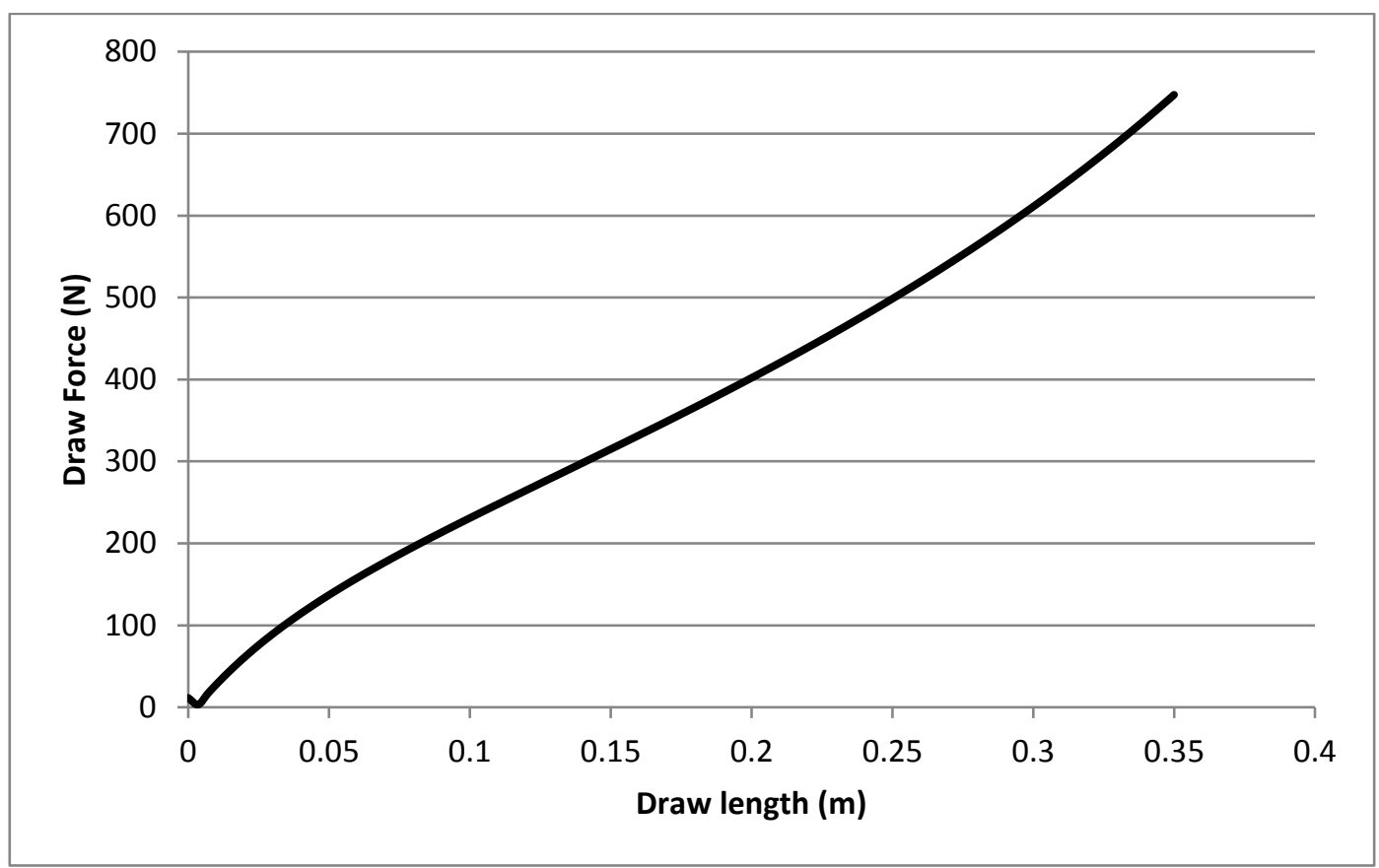

Figure 19 : Draw force vs. Stroke length for new limb design

The stiffness for the new cross-bow at $0.25 \mathrm{~m}$ deflection is $4131 \mathrm{~N} / \mathrm{m}$ (2 limbs) estimated using FEA. The new limb is stiffer than required at $3830 \mathrm{~N} / \mathrm{m}$. The energy delivered by the limb is 128J calculated using Eq. 11. Hence the limb will easily fulfil the design requirements. The FEA strain in the limb has changed slightly due to increased cross section, the strain value in the different layers are given in Table 5 and easily satisfy the factor of safety requirements.

\section{Conclusions}

A composite crossbow limb was designed to a predetermined specification, manufactured and tested. The design was then optimised using FEA. Five different design concepts were considered for their advantages and shortcomings. The linear beam theory suggested that a hybrid composite beam would be the best option, with UD aramid for the top layer (loaded in 
tension) of the limb and UD E-glass for the bottom layer (compression side) as aramid has poor compressive failure strain $(0.32 \%)$ [16].

The designed limb was manufactured by the resin infusion. This gave a good quality product. The fibre volume fraction for the aramid layer was found to be $65 \%$ and for the E-glass layer it was $60 \%$.

The deflection response and the strain in the limb during incremental loading were recorded. A FEA model of the tested sample gave simulation results which matched the experimental results. Reverse calculations revealed that the energy delivered by the limb was too low. The design was optimised by increasing the stiffness of the limb at a given deflection force in the FEA model. This methodology can be used to design and optimise products with similar characteristics (storing and releasing energy) to the crossbow such as leg prosthesis, leaf springs etc.

The Poisson's ratio of the limb was observed to decrease with increased strain.

Because of the time constraints further analysis of out of plane shear stresses at load introduction and reaction point was not carried out and the possibility of delamination near the dropped ply at the clamp position was also not considered. Fatigue life assessment of limb was not carried out.

\section{Acknowledgements}

This work was performed in the context of an assignment for module MATS 320 Composites Engineering on the BEng (Honours) Mechanical Engineering with Composite degree course. The authors acknowledge the input from other members of the assignment team (John Woods and Xavier Dubreuil). The authors are further grateful for support by the ACMC technical team (Richard Cullen, Greg Nash and Terry Richards). The authors are grateful for the helpful comments made by the referees. 
Appendix 1: Composite Mechanical Properties

Table A1: Fibre and matrix properties (from Daniel and Ishai [17]),

\begin{tabular}{|l|c|c|c|c|c|}
\hline & Aramid & E-glass & Carbon & \multicolumn{2}{|c|}{ Matrix } \\
\hline $\boldsymbol{E}_{11 f}$ & $131 \mathrm{GPa}$ & $73 \mathrm{GPa}$ & $230 \mathrm{GPa}$ & $\boldsymbol{E}_{\boldsymbol{m}}$ & $3 \mathrm{GPa}$ \\
\hline $\boldsymbol{E}_{22 f}$ & $7 \mathrm{GPa}$ & $73 \mathrm{GPa}$ & $15 \mathrm{GPa}$ & & - \\
\hline $\boldsymbol{G}_{12 f}$ & $21 \mathrm{GPa}$ & $30 \mathrm{GPa}$ & $27 \mathrm{GPa}$ & $\boldsymbol{G}_{\boldsymbol{m}}$ & $1.11 \mathrm{GPa}$ \\
\hline $\boldsymbol{G}_{23 f}$ & - & $30 \mathrm{GPa}$ & $7 \mathrm{GPa}$ & & - \\
\hline $\boldsymbol{v}_{12 f}$ & 0.33 & 0.23 & 0.2 & $\boldsymbol{V}_{\boldsymbol{m}}$ & 0.35 \\
\hline Density & $1450 \mathrm{Kg} / \mathrm{m}^{3}$ & $2540 \mathrm{Kg} / \mathrm{m}^{3}$ & $1810 \mathrm{Kg} / \mathrm{m}^{3}$ & & $1158 \mathrm{~kg} / \mathrm{m}^{3}$ \\
\hline Failure Strain & $2.30 \%$ & $2.60 \%$ & $1.10 \%$ & & $2.33 \%$ \\
\hline
\end{tabular}

Table A2: Composite material properties calculated using rule of mixture,

\begin{tabular}{|l|r|r|r|r|}
\hline & \multicolumn{2}{|c|}{ Aramid } & \multicolumn{2}{c|}{ E-glass } \\
\hline $\boldsymbol{V}_{\boldsymbol{f}}$ & $\mathbf{5 5 \%}$ & $\mathbf{6 5 \%}$ & $\mathbf{5 5 \%}$ & $\mathbf{6 0 \%}$ \\
\hline $\boldsymbol{E}_{\boldsymbol{1 1}}$ & $73.4 \mathrm{GPa}$ & $86.2 \mathrm{GPa}$ & $41.50 \mathrm{GPa}$ & $45.00 \mathrm{GPa}$ \\
\hline $\boldsymbol{E}_{\mathbf{2 2}}$ & $4.83 \mathrm{GPa}$ & $5.25 \mathrm{GPa}$ & $11.56 \mathrm{GPa}$ & $13.22 \mathrm{GPa}$ \\
\hline $\boldsymbol{E}_{\mathbf{3 3}}$ & $4.83 \mathrm{GPa}$ & $5.25 \mathrm{GPa}$ & $11.56 \mathrm{GPa}$ & $13.22 \mathrm{GPa}$ \\
\hline $\boldsymbol{G}_{\boldsymbol{1 2}}$ & $3.29 \mathrm{GPa}$ & $4.24 \mathrm{GPa}$ & $3.43 \mathrm{GPa}$ & $3.91 \mathrm{GPa}$ \\
\hline $\boldsymbol{G}_{\boldsymbol{1 3}}$ & $3.73 \mathrm{GPa}$ & $4.70 \mathrm{GPa}$ & $3.89 \mathrm{GPa}$ & $4.37 \mathrm{GPa}$ \\
\hline $\boldsymbol{G}_{23}$ & $2.32 \mathrm{GPa}$ & $2.89 \mathrm{GPa}$ & $2.36 \mathrm{GPa}$ & $2.63 \mathrm{GPa}$ \\
\hline $\boldsymbol{v}_{\boldsymbol{1 2}}$ & 0.34 & 0.34 & 0.28 & 0.28 \\
\hline $\boldsymbol{v}_{21}$ & 0.02 & 0.02 & 0.08 & 0.08 \\
\hline $\boldsymbol{v}_{\boldsymbol{1 3}}$ & 0.34 & 0.34 & 0.28 & 0.28 \\
\hline $\boldsymbol{v}_{\mathbf{2 3}}$ & 0.33 & 0.33 & 0.28 & 0.27 \\
\hline $\boldsymbol{v}_{\mathbf{3 1}}$ & 0.02 & 0.02 & 0.08 & 0.08 \\
\hline
\end{tabular}




\section{References}

[1] Dave Richard. Automotive suspension systems benefit from composites. Reinforced Plastics, 2003; 47(11): 18-21.

[2] Mahmood M. Shokrieh and Davood Rezaei. Analysis and optimisation of a composite leaf spring. Composite Structures, 2003; 60: 317-325.

[3] K Easterling, Advanced Materials for Sports Equipment, London: Chapman and Hall, 1993.

[4] M Jenkins, Materials in Sports Equipment - volume 1, Cambridge: Woodhead Publishing, 2003.

[5] A Subic, Materials in Sports Equipment - volume 2, Cambridge: Woodhead Publishing, 2007.

[6] Anthony Grant. Sporting Composites. Reinforced Plastics, 2005; 49(5): 46-49.

[7] Bill Benjamin. Composite baseball bats with striking features. Reinforced Plastics, 2002; 46(9): 52-55.

[8] B.W. Kooi and C.A. Bergman. An Approach to the study of ancient archery using mathematical modelling. Antiquity, 1997; 71(271): 124-134.

[9] B.W. Kooi. On the mechanics of some replica bows. Journal of the Society of ArcherAntiquaries, 1993; 36: 14-18.

[10] B.W. Kooi and J.A. Sparenberg. On the static deformation of a bow. Journal of Engineering Mathematics, 1980;. 14(1): 27-45.

[11] Instruction Manual. Excalibur Crossbow Inc., undated.

[12] Christopher J. McCauley (Editor). Machinery’s Handbook. Industrial Press Inc, 2000.

[13] D. Hull and T.W. Clyne. An Introduction to Composite Materials. Cambridge: Cambridge University Press, 1996.

[14] Kevin Potter. An Introduction to Composite Products: design, development and manufacture. London: Chapman \& Hall, 1997.

[15] MG Dobb, DJ Johnson and BP Saville. Structural aspects of high modulus aromatic polyamide fibres. Philosophical Transactions of the Royal Society of London, 1980; A294(1411): 483-485.

[16] M.C. Andrews, D. Lu and R.J. Young. Compressive properties of aramid fibres. Polymer 1996; 38(10); 2379-2388. 
[17] Isaac M. Daniel and Ori Ishai. Engineering Mechanics of Composite Materials. Oxford: Oxford University Press, 2006.

[18] Ferdinand P. Beer, E. Russell Johnston and John T. Dewolf. Mechanics of Materials. McGraw Hill, 2005.

[19] Erol Sancaktar and Methieu Gratton. Design, analysis and optimization of composite leaf springs for light vehicle application. Composite Structures, 1999; 44(2-3): 195-204.

[20] B.T. Áström. Manufacturing of Polymer Composites. London: Chapman \& Hall, 1997.

[21] Christopher Williams, John Summerscales and Stephen Grove. Resin Infusion under Flexible Tooling (RIFT): a review. Composites Part A: Applied Science and Manufacturing, 1996; $27 \mathrm{~A}(7):$ 517-524.

[22] J Summerscales and T J Searle. Review: Low pressure (vacuum infusion) techniques for moulding large composite structures. Proc IMechE Part L: Journal of Materials: Design and Applications, 2005; L219(1): 45-58.

[23] D Cripps, T J Searle and J Summerscales, Open Mould Techniques for Thermoset Composites, In R Talreja and J-A Månson (editors): Comprehensive Composite Materials Encyclopaedia, volume 2: Polymer Matrix Composites, Elsevier Science, Oxford, July 2000, Chapter 21, pp 737-761.

[24] Markus Feiler, Wolfgang Dudenhausen and Lazarula Chatzigeorgiou. Manufacturing of primary aircraft structures with vacuum assisted resin infusion. Society of Manufacturing Engineers ICCM-14 (2003).

[25] ASTM D2584-02 Standard Test Method for Ignition Loss of Cured Reinforced Resins.

[26] Albert S. Kobayashi. Handbook on Experimental Mechanics. Society for Experimental Mechanics, 1993.

[27] J Summerscales and S. A. Fry. Poisson's ratio in fibre-reinforced polymer composite with a high void content. Journal of Material Science Letters, 1994; 13(12): 912-914.

[28] Hasan Yildiz and Mehmet Sarikanat. Finite-element analysis of thick composite beams and plates. Composite Science and Technology, 2001; 61(12): 1723-1727.

[29] Vince Adams and Abraham Askenazi. Building Better Products with Finite Element Analysis. Albany (NY): Onword Press, (1998).

[30] Abaqus Theory Manual. Version 6.7. (2007)

[31] Abaqus Analysis User's Manual. Version 6.7. (2007) 
Published in Composites Part B: Engineering, April 2009, 40(3), 249-257. DOI 10.1016/j.compositesb.2008.10.004

[32] Trevor Hellen. How to - Use Elements Effectively. NAFEMS Ltd, (2003).

[33] Andrew D. Crocombe. How to - Tackle Non-Linear Finite Element Analysis. NAFEMS Ltd, 2002.

[34] http://www.mcmc-uk.com/prod-data-sheet/sr-8100-infusion-uk.pdf (10 February 2007)

[35] Joe D. Hoffman. Numerical Methods for Engineers and Scientists. Marcel Dekker, 2001. 